\title{
Xenografting as a Tool to Preserve Endangered Species: Outcomes and Challenges in Model Systems
}

\author{
Paula C. Mota, ${ }^{1}$ João Ramalho-Santos, ${ }^{1}$ and Stefan Schlatt ${ }^{2}$ \\ ${ }^{1}$ Center for Neuroscience and Cell Biology, Department of Life Sciences, University of Coimbra, P.O. Box/Apartado 3046, \\ 3001-401 Coimbra, Portugal \\ ${ }^{2}$ Centre of Reproductive Medicine and Andrology, University of Münster, Domagkstraße 11, 48149 Münster, Germany
}

Correspondence should be addressed to Paula C. Mota, pccrmota@yahoo.com

Received 1 June 2010; Accepted 16 August 2010

Academic Editor: Ali Honaramooz

Copyright (c) 2011 Paula C. Mota et al. This is an open access article distributed under the Creative Commons Attribution License, which permits unrestricted use, distribution, and reproduction in any medium, provided the original work is properly cited.

\begin{abstract}
The use of testis tissue xenografting as a valuable tool to rescue endangered and genetically valuable individuals that die young or otherwise fail to produce sperm has been the subject of much interest. Although the technique has been successfully applied to a wide variety of species, little is known about what determines the outcome. Furthermore, to improve the applicability of xenografting, new methods to preserve and transport testis tissue from valuable animals are emerging. However, one major issue remains: the application of xenografting implies the development of subsequent ART techniques to produce offspring from the recovered material. This paper focuses on these three aspects of testis tissue xenografting as a tool for rescuing endangered and valuable genetic pools.
\end{abstract}

\section{Introduction}

Xenografting is the transplantation of tissues across a species barrier, that is, from one species to another. Testis grafting was described in the early twentieth century, not as a tool to rescue fertility but rather to rescue prominent men from old age, claiming that it restored physical and intellectual abilities [1]. The technique fell into ridicule and was forgotten until the twentieth century, when it was rediscovered as a tool to study spermatogenesis and testis endocrine function [2-4]. In 2002 Honaramooz and colleagues boosted interest in the technique when they described the production of functional sperm from several mammalian species in testis grafts placed in immunodeficient mice ( $\mathrm{NCr} n u / n u$ ) [5]. Subsequently live progenies were obtained using sperm extracted from grafts of immature mouse and rabbit testes by intracytoplasmic sperm injection (ICSI) and embryo transfer $[6,7]$. These results suggested new applications for the methodology, including preserving fertility in young cancer patients and rescuing genetic material from endangered or rare transgenic animals.

\section{Animal Models for Endangered Species}

The loss of genetic diversity due to infertility or to the premature death of valuable individuals is a significant problem in animal conservation programs. Current attempts to address this problem through assisted reproduction involve collection of spermatozoa from live or recently deceased males. Testis tissue xenografting presents two major benefits when compared to sperm banking: it can be used for the study of spermatogenesis and testicular maturation in species which are difficult to manipulate or ethically restricted [8], and it provides a previously unavailable system to obtain spermatozoa from immature animals. Importantly, xenografting seems to preserve the testicular microenvironment, as evaluated in a porcine model by comparing gene expression patterns in development-matched grafted and donor tissue [9]. Groups interested in conservation issues have extended this technique to animal models representative of different subsets of animals, ranging from ungulate herbivores to carnivores and from seasonal to nonseasonal animals. Although there are less studies in the literature 
involving ovarian tissue xenografting in model species for endangered animals, the available information has been eloquently reviewed by Paris and Schlatt [10]. Rodent species have been extensively and successfully used in testis tissue xenograft experiments, including model mice and rats, or seasonal animals such as the golden hamster $[5,7,11-$ 13].

Donor tissue from 1 to 4 week-old goats, an ungulate herbivore, was used in the first experiment by Honoramooz and coworkers in 2002, resulting in the development from an immature state to full spermatogenesis, with seminiferous tubules showing normal stages of germ cell development [5]. Furthermore, significant amounts of mature and viable sperm (67 millions sperm per gram of tissue recovered) were collected from the grafts. Xenografting using testis of immature bulls was described [14], but in this case the number of tubules that is able to produce elongating spermatids is very low (maximum 10\% of all seminiferous tubules recovered), and further experiments were later performed in an attempt to improve xenograft success [14-17]. However in the only attempt made to recover haploid cells from grafts of an endangered bovid, the banteng calf (Bos javanicus), no round or elongating spermatids were observed after 15 months of grafting, although spermatocytes were observable after 3 months, indicating spermatogenesis arrest [18].

Sheep have also been used as a model for endangered ungulates. Sheep graft development in an immunocompromised mouse presented higher success than bovine testis xenografts, and in fact, followed the same developmental timing as normal testis [19]. Other studies were carried out using smaller or bigger sheep testis grafts, alone or cografted with spermatogonia [20]. Pigs have been extensively used in xenograft experiments $[9,21-23]$ culminating in the production of live offspring [24]. Finally, spermatogenic differentiation following horse testis tissue grafting in nude or SCID mice ranged from no differentiation to progression through meiosis with appearance of haploid cells, depending on the age of the donor, with best results in grafts of peripubertal animals. For more mature donor testis samples where spermatogenesis had progressed through meiosis with appearance of haploid cells, graft development did not progress beyond mitotic division [25].

Limited studies have been conducted in other species. Snedaker and coworkers [26] extended the use of the technique to carnivores demonstrating development of spermatogenesis and collection of sperm from grafts of immature domestic cats, as a model for endangered felines. The dog was also used as a model for endangered canids, with recovery of approximately 36 million sperm per gram of tissue when immature tissue was used for xenografting [27]. The genetic potential of endangered birds may also eventually be preserved using xenografting, although at this time point only allografting of testicular tissue of day-old chicks was tested, resulting in functional seminiferous tubules that produced sufficient sperm to fertilize eggs, producing donor-derived offspring [28].

\section{Explaining Xenograft Outcomes}

The reports of xenograft success described above always include a major limitation: only testicular tissue from immature animals gave rise to sperm. The success rate of xenografts from pubertal or adult animals is minimal or nonexistent in the various species tested (Figure 1). Kim and coworkers used cat testis tissue from immature (1 to 8 weeks), prepubertal ( 9 to 16 weeks), pubertal (5 to 7 months), and adult animals. They observed that the success of xenografting decreased abruptly when tissue was recovered from pubertal animals (only one graft presented haploid cells after 50 weeks of grafting), and all the grafts from adult animals degenerated after 50 weeks following xenografting [29]. The same kind of observations was made using dog testis [27].

In a more comprehensive study Arregui and coworkers presented results from adult testis graft development using several species. Pigs and goats, animals with a greater daily sperm output per gram of testis tissue (compared to bulls and rhesus monkey), showed more rapid degeneration postgrafting with no tubular structures remaining. In donor tissue with less intense spermatogenesis at the time of grafting (bulls and rhesus monkeys (Macaca mulatta)), seminiferous tubule degeneration was slower, but no somatic or germ cells remained in the tubules after 24 weeks. In this same paper donkey and rhesus monkey subadult testis tissue survived in the nude mice and produced elongating spermatids after 24 weeks [30].

All these studies raised the question of what makes xenografts develop and produce sperm in nude mice. Can we manipulate existing protocols in order to increase sperm retrieval?

3.1. Hormonal/Endocrine Environment. Before the success of xenografting many believed that the endocrine environment of the nude mice would not be able to support the development of spermatogenesis, given that the regulation of the secretion pattern of the hypothalamo-pituitary hormones [31], as well as, hormones and receptors themselves, differs between species [32]. However there is only one documented species where this problem actually occurred, the marmoset (Callithrix jacchus) [11, 33]. It was hypothesized that a mutation in the LH receptor prevented recognition and signaling through luteinizing hormone caused this xenograft failure [34]. However, neither the administration of human chorionic gonadotropin (a substitute for LH signaling in the marmoset) to nude mice, nor cografting with hamster testis tissue, which restores blood and local testosterone levels to normal, recovered spermatogenesis in these grafts [33]. Low survival of marmoset testis tissue after collection was eliminated as a cause for arrested xenograft development in the nude mice given that autologous transplant of immature testicular tissue to the scrotal skin resulted in the production of spermatozoa [35]. The same paper also discussed temperature (in terms of graft localization) as a factor influencing spermatogenesis in the grafts, pointing towards a more intricate regulation of spermatogenesis in marmosets [35]. 


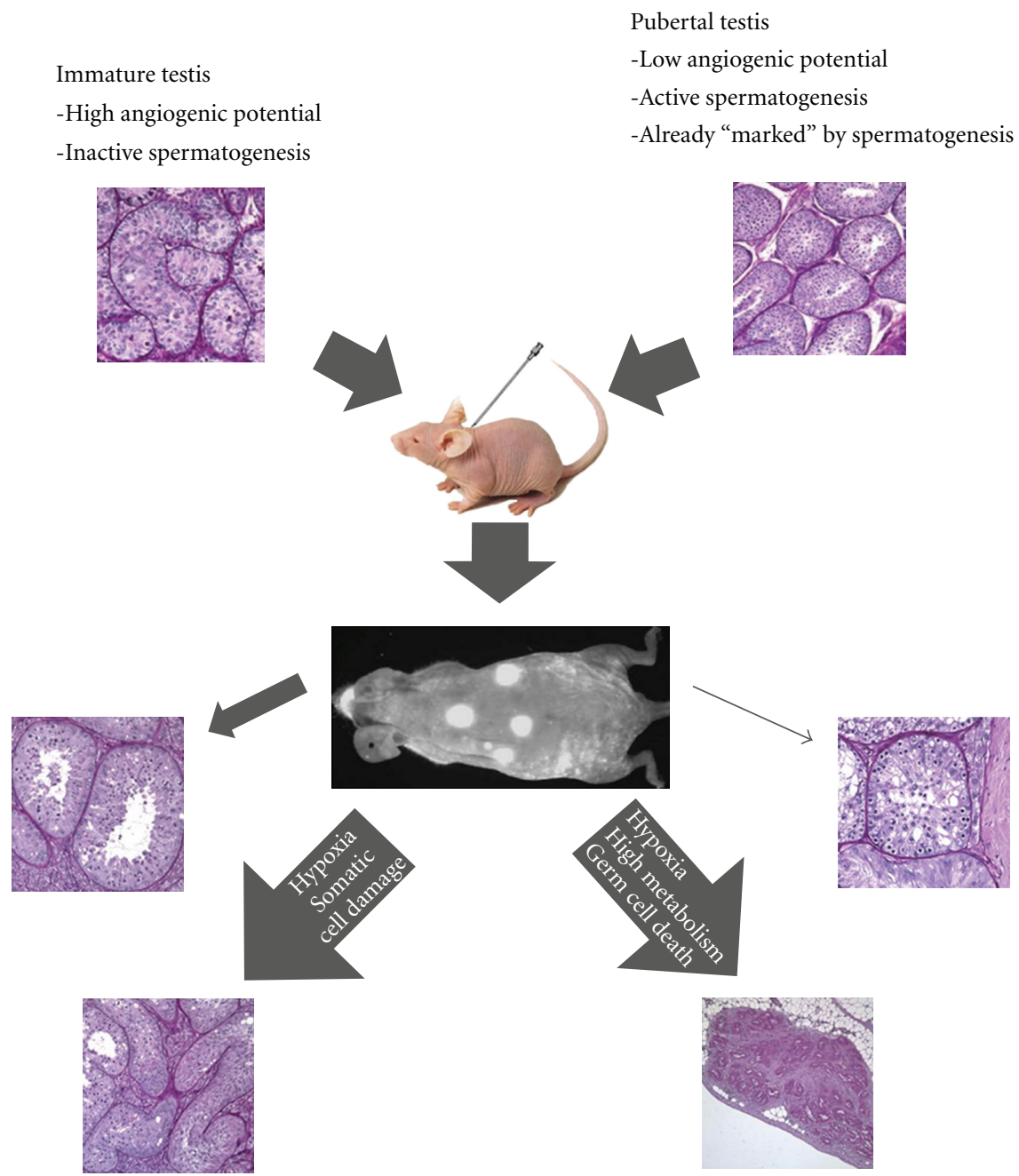

Figure 1: Potential of testis xenograft from immature and pubertal animals. The histology pictures represent cat testis and cat testis xenografts stained with Hematoxylin/Periodic acid/Schiff reagent (Mota et al., unpublished data). The amplitude of arrows is representative of percentage of seminiferous tubules with the illustrated outcome.

In order to determine if the regulatory mechanisms of the hypothalamus/pituitary-testis axis would interfere with graft survival, development studies were also carried out using castrated and noncastrated nude mice as graft receptors. Castration of recipients has been reported to be absolutely necessary for successful development of spermatogenesis in rhesus monkey testis xenografts [36] while in bovine xenografts successful restoration of complete spermatogenesis has been reported in both intact and castrated recipients [17]. The regulation of the hypothalamus-pituitary axis was further tested using immature testis from boars. Kaneko and coworkers describe the establishment of a feedback loop 60 days postgrafting between the castrated mouse hypothalamus-pituitary axis and the grafted porcine tissue, with testosterone and FSH levels similar to those of intact mice. Only inhibin-alpha showed an increase in relation to intact mice [37]. However, when murine testis tissue is grafted in castrated nude mice, the establishment of the same feedback occurs in 2 weeks, demonstrating the maintenance of species-specific characteristics in the grafts [7].
The early onset of meiosis in the xenografts of very immature testis in relation to the normal development in the donor species is thought to be related to the endocrine environment. Many authors believe this acceleration in spermatogenesis is caused by the sudden exposure of the grafted immature testis tissue to an adult endocrine profile in the recipient mouse $[5,7,38]$. Regardless of this first response, there are still species-specific differences in the time needed to obtain sperm from the xenografts. In some species the entire spermatogenesis development is accelerated in the grafts, such as in the rhesus monkey [36]. Testis grafts from bulls and rams follow the same developmental timing as testis in the intact animal, while in the cat, after an initial acceleration sperm production is delayed. Snedaker and coworkers speculate that the timing of testicular maturation in the cat is inherent to the testis and therefore cannot be modified by exposure to adult levels of mouse gonadotropins or that a mismatch between donor and recipient endocrine environment occurs, resulting in insufficient hormonal support to maintain spermatogenesis $[26,29]$. 
3.2. Xenograft Nutrition and Oxygenation. When comparing spermatogenesis in grafts from the same species (bulls) but with different donor ages, the timing for restoration of spermatogenesis in grafts is constant, suggesting that spermatogenesis must be reinitiated postgrafting from spermatogonial stem cells or early differentiating spermatogonia [17]. This suggests that more differentiated cells present in xenografts die either in the pregrafting period or immediately after xenografting, probably due to insufficient nutritional and oxygen support $[17,25]$.

Like any other tissue that is transplanted to a new location, xenograft survival is also dependent on recipient tissue for nutrients and oxygen. Indeed, a significant difference in the number of blood vessels between functional and nonfunctional testis grafts indicate an essential role for angiogenesis in graft survival and development [16]. Schmidt and coworkers [16] have attempted to improve/stimulate vessel growth by treating xenografted tissue with recombinant VEGF. This treatment resulted in an increase in graft size and an increase in the percentage of seminiferous tubules with elongating spermatids. However, no differences were observed in the number or diameter of the seminiferous tubules in treated and nontreated testis tissue grafts. This pointed towards a direct role of VEGF on germ cell survival/differentiation [39]. These findings may be explained if one considers the vascularization of GFP-expressing rat testis xenografts in nude mice [12]. Because in this particular case GFP is expressed in endothelial cells, it was possible to confirm the origin of the vessels that enabled graft survival. Small vessels formed by GFP-labeled endothelial cells stretched through the fibrotic capsule formed by the nude mice to isolate the xenograft. These small vessels then connected to nude mice vessels with bigger diameter [12]. This finding implies that graft capacity to induce growth of new vessels determines its survival, and this may be determined by donor age. This hypothesis was further supported by microarray analysis of genes expressed in bovine testis at different developmental time points. Angiogenic and growth factors such as angiogenin, transgelin, thrombomodulin, early growth response 1, insulinlike growth factor 2, and insulin-like growth factor-binding protein 3 were lower in tissues from older animals [40]. Concomitantly, BrdU labeling also showed that, although proliferating endothelial cells were observed in all types of blood vessels in the adult rat testis, other characteristics typical of new blood vessel formation were missing, which may reflect a continuous high turnover of endothelial cells rather than classical angiogenesis seen in immature testis tissue [41]. On the other hand, there are some mammalian species with the same capability for angiogenesis in adult and prepubertal testis tissue, such as the golden hamster [42]. In the first week of exposure to long day photoperiod (which triggers spermatogenesis in this seasonal breeder) there is an increase in vessel density and permeability, with the de novo forming of new vessels as well as the recovery of vessels already in place before testis regression. However, when testis tissue of photoregressed animals was grafted in the nude mice, there was very limited recovery, and most of the tissue degenerated [11]. Given that spermatogenesis in the hamster testis was fully regressed [11] and that the ability to form new vessels is preserved in these animals [42], the reason for the different outcomes using immature and adult testis grafts is still unknown and seems to deny both spermatogenesis activity and angiogenic plasticity as the only causes that determine xenograft success.

\section{New Methods to Preserve Testis Tissue}

One of the challenges of xenografting testis tissue is preserving the tissue to be used when and where it is necessary. When surveying the literature there seems to be no consensus in terms of what the better cryoprotectant or cryopreservation protocol for testis tissue might be.

The first report on cryopreserved testis tissue xenografts came from Schlatt and coworkers using murine testis [11]. The grafts were equilibrated for $20 \mathrm{~min}$ in $1.5 \mathrm{M}$ dimethyl sulphoxide (DMSO), put in vials, and loaded into a programmable freezer. No obvious adverse effect of cryopreservation of the tissue was reported. Milazzo and coworkers also suggest DMSO $1.5 \mathrm{M}$ as the best cryoprotectant for prepubertal murine testis tissue after testing 19 cryopreservation protocols using DMSO and 1,2-propanediol [42]. Other results in different species seem to point in the same direction. Cryopreservation and allografting of testicular tissue of day-old chicks with 10\% DMSO (1.4 M) resulted in functional seminiferous tubules that produced sufficient sperm to fertilize eggs and give rise to donorderived offspring [28]. In rhesus monkey 1.4 M DMSO was also able to protect some of the developmental potential of the grafts, although with a reduction of xenograft survival, increase in the number of seminiferous tubules with only Sertoli cells and lower numbers of spermatogonia. However grafts cryopreserved with $0.7 \mathrm{M}$ DMSO showed no recovery, with loss of the entire population of spermatogonia. When ethylene glycol was used as a cryoprotectant the survival rate also decreased substantially [43]. The human testis tissue has been successfully cryopreserved using $0.7 \mathrm{M}$ DMSO. This has been demonstrated either using light and TEM microscopy $[44,45]$ or xenografting $[46,47]$. Xenografting is clearly a more reliable method to assess cryopreservation success, as given that different concentrations of DMSO (0.7 and $1.4 \mathrm{M}$ ) result in very different xenografting outcomes although histological morphology of thawed testis grafts at the time of xenografting was identical [43].

Interestingly, and after an extensive study of several strategies for cryopreservation of immature testis tissue, Abrishami and coworkers determined that glycerol was a better cryoprotectant for the pig. After testing programmed slow freezing with DMSO, glycerol, or ethylene glycol and solid-surface vitrification using these same cryoprotectants, these authors reported that, although not as efficiently as fresh testis tissue, programmed slow-freezing and vitrification using glycerol resulted in grafts which developed well, with spermatogenesis restored to the phase of round and elongated spermatids after 16 weeks of grafting [23]. These results suggest that each species/family of species may need a different cryopreservation protocol, with a concomitant need to adjust for concentration of cryoprotectant or even 
adapting different cryoprotectants. These differences may be related to testicular architecture (\% of fibrotic tissue), morphology and even lipid composition [23].

Although it has some drawbacks, mainly in terms of time to send and xenograft the tissue, another method to preserve testis tissue is cooling it to approximately $4^{\circ} \mathrm{C}$. This methodology was first described by Schlatt and coworkers who cooled murine testicular tissue for 24 hours [11]. In the rhesus monkey, cooling of testicular tissue for 24 hours also presented the same results as fresh grafting [43]. The cooling time was then extended to 48 or $72 \mathrm{~h}[9,23]$. The authors $[9,23]$ showed that the developmental competence of tissues cooled for 24,48 , or $72 \mathrm{~h}$ was comparable or higher than that of fresh testis tissue, speculating that low but stable metabolism prior to grafting induced by proper cooling might help prepare the graft for the hypoxic conditions that probably exist immediately after xenografting $[9,23]$.

\section{Development of ART Technologies Necessary for Full Usage of Xenografting Methodology}

Xenografting allows sperm production from immature testicular tissue. However, this does not necessarily mean recovery of the donor genetic pool. As shown by Honaramooz et al., porcine spermatozoa obtained from xenografts were able to fertilize oocytes but at a lower percentage (24\%) in comparison with testicular, epididymal, and ejaculated spermatozoa $(58 \%, 68 \%$, and $62 \%$, resp.). The embryos produced developed to the blastocyst stage but also at a lower rate ( $8 \%$ versus $22 \%, 27 \%$, and $25 \%$, resp.) [22]. These results, although seemingly poor, were only possible because intracytoplasmic sperm injection (ICSI) and in vitro culture of early embryos had already been developed in the pig.

In fact, the use of xenografting to recover sperm implies in vitro fertilization using mature oocytes, culture of the early embryo, and embryo transfer to an appropriate recipient female, with or without estrus synchronization. In mice all these steps have been established and are performed with a high success rate, but this is not the case for all species. For many species these assisted reproduction techniques are still unavailable or represent a high health risk for the female partner limiting xenograft application.

In farm animals, models species for endangered ungulates, all the steps necessary for using sperm derived from xenografts have also been described, although with lower success rates than those obtained for mice. However, many articles describe developmental abnormalities that manifest themselves during pregnancy, after birth, or later in the life of the offspring produced by assisted reproduction techniques. The number of abnormalities increases with increasing number of steps performed in vitro, which may suggest less than ideal culture conditions (reviewed by [48]). Abnormal ploidy is also detected in pig embryos after in vitro oocyte maturation [49].

In the domestic cat and some endangered felids some or all the steps have either been described or are within the realm of possibility. Pope and coworkers described the production of live offspring from two endangered felid species, the fishing cat (Prionailurus viverrinus) and caracals
(Caracal caracal), using assisted reproduction techniques. Ovarian stimulation was induced with gonadotropins, and preovulatory oocytes and immature oocytes were retrieved by laparoscopy. The preovulatory oocytes recovered were used directly for in vitro fertilization experiments while immature oocytes were matured in vitro and also used to produce embryos. Of the 12 embryo transfer procedures done in fishing cats, one pregnancy was obtained, and one live kitten was born. In caracals a total of 46 embryos were transferred to six recipients, one of which delivered two live kittens. Cryopreserved caracal embryos were also transferred to nine recipients, and a total of three kittens were born from the three pregnancies established [50]. ICSI has also been described using ejaculated cat spermatozoa [51]. However, when testicular sperm is used for this procedure the number of blastocysts obtained is reduced although this problem may be solved by the injection of midpieces from ejaculated sperm together with the head of a testicular sperm [52]. From this and other attempts (reviewed by $[53,54]$ ) the conclusion to be drawn is that, although all steps are possible, and some have been demonstrated in wild felids, the success rate is very low, and this is clearly the major drawback in the application of xenografting to rescue the genetic pool of wild felids. In canids, another carnivore family, the insurmountable issue so far seems to be in vitro oocyte maturation which limits the amount of oocytes available, and thus the possibilities for in vitro fertilization [55].

\section{Conclusion}

Although promising data is now available in many animal models for endangered species, xenografting and all other associated techniques have to be tested for each individual species on a trial and error basis, since species variability is almost certain to be an important factor in terms of perfecting successful protocols. The transmission of genetic abnormalities to the offspring generated using xenografting must also be evaluated. At this time, testis tissue xenografting application for offspring production represents a major economical and time-consuming effort for conservation programs and should only be suggested for species where the low number of animals and low genetic variability of the population makes the individual variability of one male so important, such as in the case of the Iberian lynx (Lynx pardinus). Moreover, given that xenografting is much more successful in immature tissue, special attention should be paid to fragile and rare cubs, who are clearly good candidates for this procedure in case of developmental failure or untimely death.

However, broader use of xenografting arises from the possibility of subjecting the "same" tissue (one testis sample) to different stimuli, drugs or environmental contaminants. This represents a step forward in the unraveling of different regulatory mechanisms, in drug selection for treatments or in evaluating toxic effects in testis development and spermatogenesis. This is especially true for species that have mostly been unavailable/sealed for such experiments until now, including humans, a not so endangered species. 


\section{References}

[1] S. Voronoff, Rejuvenation by Grafting, Adelphi, New York, NY, USA, 1925, translation edited by F. F. Imianitoff.

[2] C. D. Turner and H. Asakawa, "Complete spermatogenesis in intratesticular homotransplants of fetal and neonatal testes in the rat," Proceedings of the Society for Experimental Biology and Medicine, vol. 112, pp. 132-135, 1963.

[3] T. Kuopio, P. O. Savouras, L. J. Pelliniemi, and I. T. Huhtaniemi, "Transplantation of newborn rat testis under the kidney capsule of adult host as a model to study the structure and function of Leydig cells," Journal of Andrology, vol. 10, no. 5, pp. 335-345, 1989.

[4] L. Johnson, L. C. Suggs, Y. M. Norton, and W. C. Zeh, "Effect of developmental age or time after transplantation on Sertoli cell number and testicular size in inbred Fischer rats," Biology of Reproduction, vol. 54, no. 5, pp. 948-959, 1996.

[5] A. Honaramooz, A. Snedaker, M. Boiani, H. Schöler, I. Dobrinski, and S. Schlatt, "Sperm from neonatal mammalia testes grafted in mice," Nature, vol. 418, no. 6899, pp. 778-781, 2002.

[6] T. Shinohara, K. Inoue, N. Ogonuki et al., "Birth of offspring following transplantation of cyropreserved immature testicular pieces and in-vitro microinsemination," Human Reproduction, vol. 17, no. 12, pp. 3039-3045, 2002.

[7] S. Schlatt, A. Honaramooz, M. Boiani, H. R. Schöler, and I. Dobrinski, "Progeny from sperm obtained after ectopic grafting of neonatal mouse testes," Biology of Reproduction, vol. 68, no. 6, pp. 2331-2335, 2003.

[8] R. Rathi, W. Zeng, S. Megee, A. Conley, S. Meyers, and I. Dobrinski, "Maturation of testicular tissue from infant monkeys after xenografting into mice," Endocrinology, vol. 149, no. 10, pp. 5288-5296, 2008.

[9] W. Zeng, A. K. Snedaker, S. Megee et al., "Preservation and transplantation of porcine testis tissue," Reproduction, Fertility and Development, vol. 21, no. 3, pp. 489-497, 2009.

[10] M. C. J. Paris and S. Schlatt, "Ovarian and testicular tissue xenografting: its potential for germline preservation of companion animals, non-domestic and endangered species," Reproduction, Fertility and Development, vol. 19, no. 6, pp. 771-782, 2007.

[11] S. Schlatt, S. S. Kim, and R. Gosden, "Spermatogenesis and steroidogenesis in mouse, hamster and monkey testicular tissue after cryopreservation and heterotopic grafting to castrated hosts," Reproduction, vol. 124, no. 3, pp. 339-346, 2002.

[12] S. Schlatt, B. Westernströer, K. Gassei, and J. Ehmcke, "Donorhost involvement in immature rat testis xenografting into nude mouse hosts," Biology of Reproduction, vol. 82, no. 5, pp. 888-895, 2010.

[13] J. Ehmcke, K. Gassei, and S. Schlatt, "Ectopic testicular xenografts from newborn hamsters (Phodopus sungorus) show better spermatogenic activity in aged compared with young recipients," Journal of Experimental Zoology A, vol. 309, no. 5, pp. 278-287, 2008.

[14] J. M. Oatley, D. M. de Avila, J. J. Reeves, and D. J. McLean, "Spermatogenesis and germ cell transgene expression in xenografted bovine testicular tissue," Biology of Reproduction, vol. 71, no. 2, pp. 494-501, 2004.

[15] J. M. Oatley, J. J. Reeves, and D. J. McLean, "Establishment of spermatogenesis in neonatal bovine testicular tissue following ectopic xenografting varies with donor age," Biology of Reproduction, vol. 72, no. 2, pp. 358-364, 2005.
[16] J. A. Schmidt, J. M. de Avila, and D. J. McLean, "Effect of vascular endothelial growth factor and testis tissue culture on spermatogenesis in bovine ectopic testis tissue xenografts," Biology of Reproduction, vol. 75, no. 2, pp. 167-175, 2006.

[17] S. Huang, B. L. Sartini, and J. E. Parks, "Spermatogenesis in testis xenografts grafted from pre-pubertal Holstein bulls is re-established by stem cell or early spermatogonia," Animal Reproduction Science, vol. 103, no. 1-2, pp. 1-12, 2008.

[18] A. Honaramooz, W. Zeng, R. Rathi, J. Koster, O. Ryder, and I. Dobrinski, "193 testis tissue xenografts to preserve germ cells from a cloned banteng calf," Reproduction, Fertility and Development, vol. 17, no. 2, p. 247, 2005.

[19] L. Arregui, R. Rathi, S. O. Megee et al., "Xenografting of sheep testis tissue and isolated cells as a model for preservation of genetic material from endangered ungulates," Reproduction, vol. 136, no. 1, pp. 85-93, 2008.

[20] J. R. Rodriguez-Sosa, R. A. Foster, and A. Hahnel, "Development of strips of ovine testes after xenografting under the skin of mice and co-transplantation of exogenous spermatogonia with grafts," Reproduction, vol. 139, no. 1, pp. 227-235, 2010.

[21] W. Zeng, G. F. Avelar, R. Rathi, L. R. Franca, and I. Dobrinski, "The length of the spermatogenic cycle is conserved in porcine and ovine testis xenografts," Journal of Andrology, vol. 27, no. 4, pp. 527-533, 2006.

[22] A. Honaramooz, X.-S. Cui, N.-H. Kim, and I. Dobrinski, "Porcine embryos produced after intracytoplasmic sperm injection using xenogeneic pig sperm from neonatal testis tissue grafted in mice," Reproduction, Fertility and Development, vol. 20, no. 7, pp. 802-807, 2008.

[23] M. Abrishami, M. Anzar, Y. Yang, and A. Honaramooz, "Cryopreservation of immature porcine testis tissue to maintain its developmental potential after xenografting into recipient mice," Theriogenology, vol. 73, no. 1, pp. 86-96, 2010.

[24] M. Nakai, H. Kaneko, T. Somfai et al., "Production of viable piglets for the first time using sperm derived from ectopic testicular xenografts," Reproduction, vol. 139, no. 2, pp. 331$335,2010$.

[25] R. Rathi, A. Honaramooz, W. Zeng, R. Turner, and I. Dobrinski, "Germ cell development in equine testis tissue xenografted into mice," Reproduction, vol. 131, no. 6, pp. 1091-1098, 2006.

[26] A. K. Snedaker, A. Honaramooz, and I. Dobrinski, "A game of cat and mouse: xenografting of testis tissue from domestic kittens results in complete cat spermatogenesis in a mouse host," Journal of Andrology, vol. 25, no. 6, pp. 926-930, 2004.

[27] M. Abrishami, S. Abbasi, and A. Honaramooz, "The effect of donor age on progression of spermatogenesis in canine testicular tissue after xenografting into immunodeficient mice," Theriogenology, vol. 73, no. 4, pp. 512-522, 2010.

[28] Y. Song and F. G. Silversides, "Production of offspring from cryopreserved chicken testicular tissue," Poultry Science, vol. 86, no. 7, pp. 1390-1396, 2007.

[29] Y. Kim, V. Selvaraj, B. Pukazhenthi, and A. J. Travis, "Effect of donor age on success of spermatogenesis in feline testis xenografts," Reproduction, Fertility and Development, vol. 19, no. 7, pp. 869-876, 2007.

[30] L. Arregui, R. Rathi, W. Zeng et al., "Xenografting of adult mammalian testis tissue," Animal Reproduction Science, vol. 106, no. 1-2, pp. 65-76, 2008.

[31] F. J. Karsh, "Reproduction in mammals," in Book 3: Hormonal Control of Reproduction, C. R. Austin and R. V. Short, Eds., pp. 1-21, Cambridge University Press, Cambridge, UK, 1997.

[32] M. D. Li and J. J. Ford, "A comprehensive evolutionary analysis based on nucleotide and amino acid sequences of the $\alpha$ - and 
$\beta$-subunits of glycoprotein hormone gene family," Journal of Endocrinology, vol. 156, no. 3, pp. 529-542, 1998.

[33] J. Wistuba, M. Mundry, C. M. Luetjens, and S. Schlatt, "CoGrafting of hamster (Phodopus sungorus) and marmoset (Callithrix jacchus) testicular tissues into nude mice does not overcome blockade of early spermatogenic differentiation in primate grafts," Biology of Reproduction, vol. 71, no. 6, pp. 2087-2091, 2004.

[34] J. Gromoll, J. Wistuba, N. Terwort, M. Godmann, T. Müller, and M. Simoni, "A new subclass of the luteinizing hormone/chorionic gonadotropin receptor lacking exon 10 messenger RNA in the new world monkey (Platyrrhini) lineage," Biology of Reproduction, vol. 69, no. 1, pp. 75-80, 2003.

[35] C. M. Luetjens, J.-B. Stukenborg, E. Nieschlag, M. Simoni, and J. Wistuba, "Complete spermatogenesis in orthotopic but not in ectopic transplants of autologously grafted marmoset testicular tissue," Endocrinology, vol. 149, no. 4, pp. 1736-1747, 2008.

[36] A. Honaramooz, M.-W. Li, M. C. T. Penedo, S. Meyers, and I. Dobrinski, "Accelerated maturation of primate testis by xenografting into mice," Biology of Reproduction, vol. 70, no. 5, pp. 1500-1503, 2004.

[37] H. Kaneko, K. Kikuchi, M. Nakai, and J. Noguchi, "Endocrine status and development of porcine testicular tissues in host mice," Journal of Reproduction and Development, vol. 54, no. 6, pp. 480-485, 2008.

[38] R. Rathi, A. Honaramooz, W. Zeng, S. Schlatt, and I. Dobrinski, "Germ cell fate and seminiferous tuble development in bovine testis xenografts," Reproduction, vol. 130, no. 6, pp. 923-929, 2005.

[39] K. C. Caires, J. de Avila, and D. J. McLean, "Vascular endothelial growth factor regulates germ cell survival during establishment of spermatogenesis in the bovine testis," Reproduction, vol. 138, no. 4, pp. 667-677, 2009.

[40] J. A. Schmidt, J. M. de Avila, and D. J. McLean, "Analysis of gene expression in bovine testis tissue prior to ectopic testis tissue xenografting and during the grafting period," Biology of Reproduction, vol. 76, no. 6, pp. 1071-1080, 2007.

[41] I. F. Lissbrant, E. Lissbrant, A. Persson, J.-E. Damber, and A. Bergh, "Endothelial cell proliferation in male reproductive organs of adult rat is high and regulated by testicular factors," Biology of Reproduction, vol. 68, no. 4, pp. 1107-1111, 2003.

[42] A. Mayerhofer, A. P. Sinha Hikim, A. Bartke, and L. D. Russell, "Changes in the testicular microvasculature during photoperiod-related seasonal transition from reproductive quiescence to reproductive activity in the adult golden hamster," Anatomical Record, vol. 224, no. 4, pp. 495-507, 1989.

[43] K. Jahnukainen, J. Ehmcke, S. D. Hergenrother, and S. Schlatt, "Effect of cold storage and cryopreservation of immature nonhuman primate testicular tissue on spermatogonial stem cell potential in xenografts," Human Reproduction, vol. 22, no. 4, pp. 1060-1067, 2007.

[44] V. Keros, B. Rosenlund, K. Hultenby, L. Aghajanova, L. Levkov, and O. Hovatta, "Optimizing cryopreservation of human testicular tissue: comparison of protocols with glycerol, propanediol and dimethylsulphoxide as cryoprotectants," Human Reproduction, vol. 20, no. 6, pp. 1676-1687, 2005.

[45] V. Keros, K. Hultenby, B. Borgström, M. Fridström, K. Jahnukainen, and O. Hovatta, "Methods of cryopreservation of testicular tissue with viable spermatogonia in pre-pubertal boys undergoing gonadotoxic cancer treatment," Human Reproduction, vol. 22, no. 5, pp. 1384-1395, 2007.

[46] C. Wyns, M. Curaba, B. Martinez-Madrid, A. Van Langendonckt, W. François-Xavier, and J. Donnez, "Spermatogonial survival after cryopreservation and short-term orthotopic immature human cryptorchid testicular tissue grafting to immunodeficient mice," Human Reproduction, vol. 22, no. 6, pp. 1603-1611, 2007.

[47] C. Wyns, A. van Langendonckt, F.-X. Wese, J. Donnez, and M. Curaba, "Long-term spermatogonial survival in cryopreserved and xenografted immature human testicular tissue," Human Reproduction, vol. 23, no. 11, pp. 2402-2414, 2008.

[48] T. G. McEvoy, F. M. Alink, V. C. Moreira, R. G. Watt, and K. A. Powell, "Embryo technologies and animal healthconsequences for the animal following ovum pick-up, in vitro embryo production and somatic cell nuclear transfer," Theriogenology, vol. 65, no. 5, pp. 926-942, 2006.

[49] K. Kikuchi, N. Kashiwazaki, T. Nagai et al., "Selected aspects of advanced porcine reproductive technology," Reproduction in Domestic Animals, vol. 43, supplement 2, pp. 401-406, 2008.

[50] C. E. Pope, M. C. Gomez, and B. L. Dresser, "In vitro embryo production and embryo transfer in domestic and non-domestic cats," Theriogenology, vol. 66, no. 6-7, pp. 15181524, 2006.

[51] M. C. Gómez, C. E. Pope, R. Harris, A. Davis, S. Mikota, and B. L. Dresser, "Births of kittens produced by intracytoplasmic sperm injection of domestic cat oocytes matured in vitro," Reproduction, Fertility and Development, vol. 12, no. 7-8, pp. 423-433, 2000.

[52] P. Comizzoli, D. E. Wildt, and B. S. Pukazhenthi, "Poor centrosomal function of cat testicular spermatozoa impairs embryo development in vitro after intracytoplasmic sperm injection," Biology of Reproduction, vol. 75, no. 2, pp. 252-260, 2006.

[53] C. E. Pope, M. C. Gómez, and B. L. Dresser, "In vitro production and transfer of cat embryos in the 21st century," Theriogenology, vol. 66, no. 1, pp. 59-71, 2006.

[54] W. F. Swanson, "Application of assisted reproduction for population management in felids: the potential and reality for conservation of small cats," Theriogenology, vol. 66, no. 1, pp. 49-58, 2006.

[55] A. K. Alhaider and P. F. Watson, "The effects of hCG and growth factors on in vitro nuclear maturation of dog oocytes obtained during anoestrus," Reproduction, Fertility and Development, vol. 21, no. 4, pp. 538-548, 2009. 

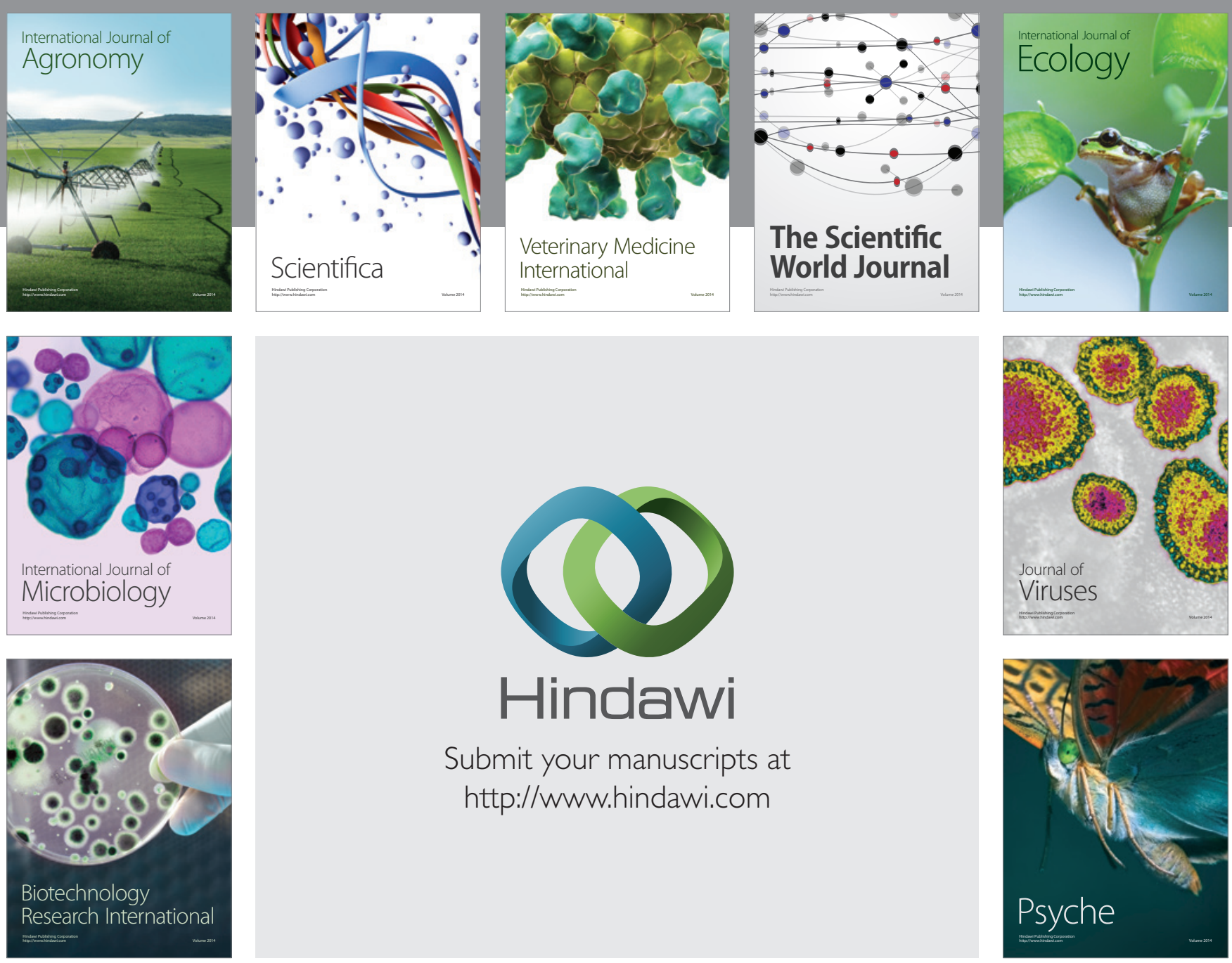

Submit your manuscripts at

http://www.hindawi.com
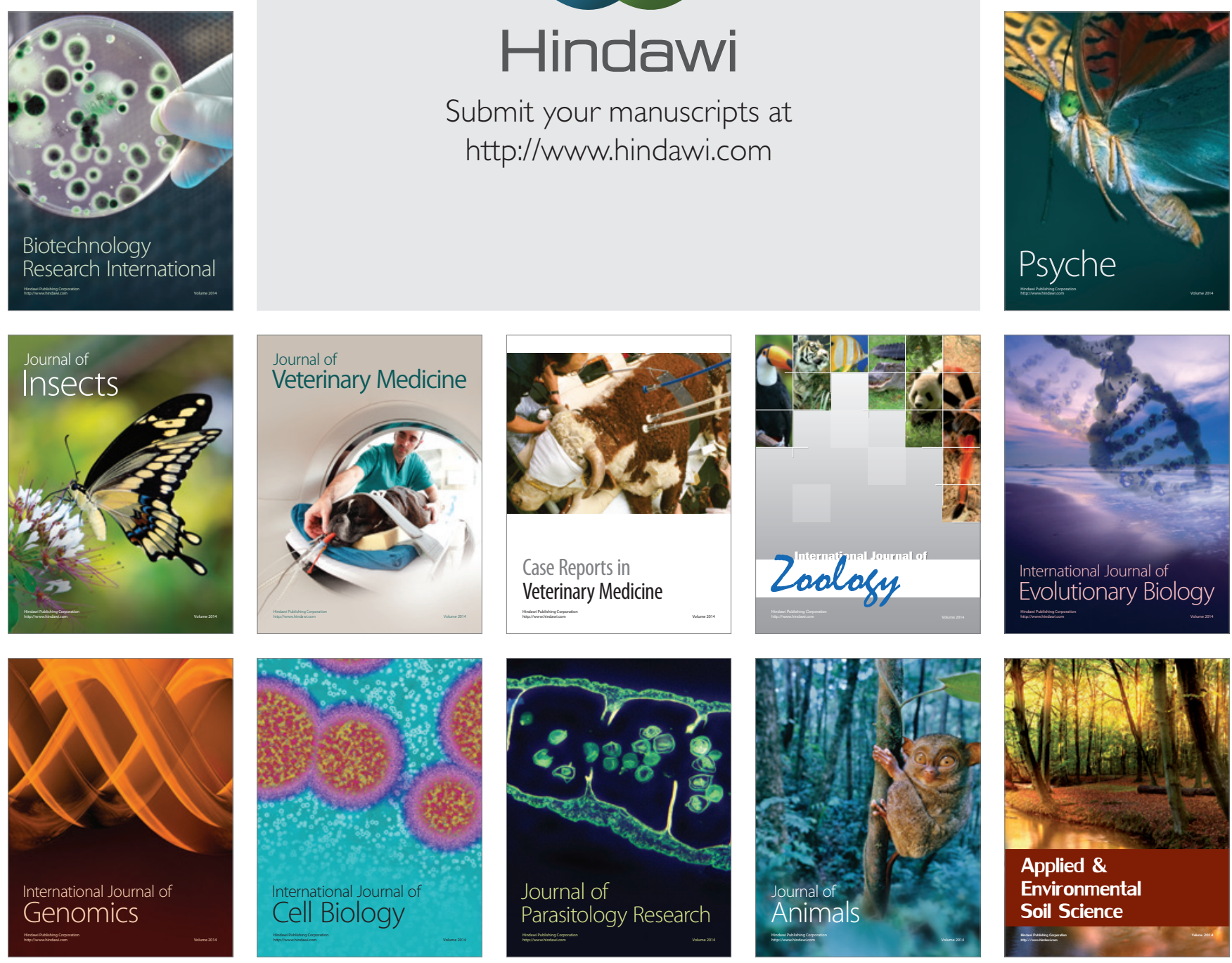